\title{
The First Clinical Trial in Tohoku University Hospital after The Great East Japan Earthquake: The Heroic Efforts of My Friend, Professor Masashi Aoki
}

\author{
Hideyuki Okano \\ Department of Physiology, School of Medicine, Keio University, Tokyo, Japan \\ (Received for publication on November 2, 2011) \\ (Revised for publication on November 28, 2011) \\ (Accepted for publication on December 16, 2011)
}

\begin{abstract}
The Great East Japan Earthquake of 2011 seriously jeopardized our collaborative research with Professor Masashi Aoki (Tohoku University School of Medicine) on the development of new therapies for amyotrophic lateral sclerosis (ALS) using hepatocyte growth factor. After the earthquake struck, Professor Aoki made a tremendous contribution to saving patients' lives and to recovering from the disastrous situation. Thanks to his strong leadership and support from many reliable colleagues, we could finally start new clinical trials for ALS patients. In this article, I wish to introduce Professor Aoki's heroic efforts. (Keio J Med 61 (1) : 3-9, March 2012)
\end{abstract}

Keywords: amyotrophic lateral sclerosis, hepatocyte growth factor, clinical trial, earthquake, supplies

\section{Introduction}

The Great East Japan Earthquake struck on March 11, 2011 , and registered a magnitude (Mw) of 9.0, the strongest in Japan in recorded history. The giant tsunami that followed the earthquake affected the Pacific coast of the Tohoku and Kanto regions and brought a disaster of truly unprecedented scale, with the loss of more than 15,000 lives. The damage to nuclear power plants caused by the tsunami induced extreme confusion in Japan, and its influence still continues to this day.

However, people living in the damaged areas are moving forward strongly and positively, attempting to restore normalcy and to emerge from the heavy blow they have been dealt. This is also the case for medical researchers and those engaged in medical care in the affected areas. The achievement of Prof. Masashi Aoki of the Department of Neurology, Tohoku University School of Medicine, who has long been my collaborator, is truly remarkable: he has started the world's first clinical trial on the treatment of amyotrophic lateral sclerosis (ALS) while continuing his efforts to recover from the disaster. Although the expression may sound hackneyed, Prof. Aoki's heroic work during these past 6 months has moved many people's hearts. I decided that I should write down these details before my memory begins to fade, and I am glad that I was asked to contribute to this special issue of the Keio Journal of Medicine on the Great East Japan Earthquake.

Study on the Treatment of ALS and Regeneration of the Injured Spinal Cord Induced by Hepatocyte Growth Factor

Before embarking on topics related to the earthquake, I would first like to introduce the study of neural regeneration that Prof. Aoki and I are engaged in. Our research group at Keio University (including the Departments of Physiology and Orthopedic Surgery) has been conducting a collaborative study with Dr. Aoki's group at Tohoku University for more than 5 years with the aim of developing a treatment for ALS and achieving regeneration of the injured spinal cord using hepatocyte growth factor (HGF). HGF is a physiologically active substance discov- 
ered by Nakamura, Ichihara and others in Japan in $1984,{ }^{1}$ and its primary sequence was elucidated by gene cloning in $1989 .^{2}$ This physiologically active protein has a variety of biological activities, including promotion of cell proliferation and migration, three-dimensional morphogenesis, inhibition of cell death and promotion of angiogenesis, and hence it facilitates the protection, regeneration and repair of various tissues and organs. A research group from Osaka University and our own group at Keio University have both confirmed the therapeutic effects of HGF gene transfer on ALS and spinal cord injury (SCI) 3,4 and we initiated a preclinical study of recombinant human HGF protein provided by Kringle Pharma, Inc. Dr. Aoki (then a lecturer) demonstrated the efficacy of recombinant human HGF (rhHGF) protein in rat models of ALS (SOD1 G93A transgenic rat) ${ }^{5,6}$ that he himself had developed and a rat SCI model (unpublished results). We then succeeded in inducing dramatic functional recovery by administration of rhHGF in a model of SCI in the common marmoset, a small New World monkey. ${ }^{7}$ With such an effective collaborative system in place, basic and preclinical studies aimed at neural regeneration began to progress relatively smoothly. At the same time, research was gaining momentum to realize Japanese-originated regenerative agents to treat SCI, cerebral infarction and ALS, with the acceleration of existing basic studies on central nervous system (CNS) regeneration using HGF, anti-IL-6 receptor antibody and stem cell transplantation ${ }^{8,9,10}$. In 2008, a collaborative research team mainly comprising our group at Keio University and a group formed by Dr. Aoki made an application to the regenerative medicine field of the "Super Special Consortia for Supporting the Development of Cutting-edge Medical Care," an initiative of the Cabinet Office, under the "Cutting-edge Medical Care Development Project for Central Nervous System Regenerative Medicine - Mainly Spinal Cord Injury," which was adopted without problems. For this research project, an industry-university collaborative team was established, consisting of members from Osaka University; Kyoto University; the Central Institute for Experimental Animals; Kringle Pharma, Inc.; Chugai Pharmaceutical Co., Ltd.; Dainippon Sumitomo Pharma Co., Ltd.; Seikagaku Corporation; and San Bio, Inc. (and also currently Teijin Ltd.), in addition to the core members from Keio University (Departments of Orthopaedic Surgery, Neurosurgery, Neurology and Physiology) and Tohoku University, and the team is engaged in the realization of CNS regenerative medicine.

Since the approval of the research proposal, a collaborative team consisting of the spinal cord regeneration group from the Departments of Orthopaedic Surgery and Physiology, Keio University, and Dr. Aoki's group has been attempting to develop treatment for ALS and spinal cord injury with HGF "from bench to bedside" and began to tackle the difficult problem of how to overcome the potential dangers to which the initiation and execu- tion of the clinical trial could expose patients. The trial was to be conducted not by a giant pharmaceutical company, but by a venture company, Kringle Pharma, Inc., and as is the case for other bio-venture companies, this company also has limited working capital, necessitating considerable fund raising to actually conduct the trial. While applying for public funds, asking venture capitalists for funding and approaching major pharmaceutical and bioscience companies, we took the necessary steps needed before actually conducting the trial, including safety tests (toxicity test of intrathecal rhHGF and pharmacokinetics tests) in macaque monkeys, establishment of the clinical trial system in Tohoku University and the fine tuning of clinical protocols. By utilizing the system of the "Super Special Consortia for Supporting the Development of Cutting-edge Medical Care," we obtained the information and know-how on what steps needed to be taken before the initiation of clinical trials and proceeded to efficiently prepare for the trial. Early in 2011, we held a pretrial consultation with the Pharmaceuticals and Medical Devices Agency (PMDA). In addition, during this period, on February 1, 2011, Dr. Aoki became a professor in the Department of Neurology, Tohoku University, succeeding Prof. Yasuo Itoyama, and this boosted our morale towards preparation for the trial. Furthermore, we came out with a relatively good feeling from the pretrial consultation with the PMDA and estimated that we could start the trial in April 2011 if everything went smoothly. Then, NHK (a broadcast station supported by the Japanese government) sought to interview us about these basic and preclinical studies and preparations for the clinical trial, and NHK news reported on the "Development of a new treatment for ALS patients in Tohoku University Hospital" on March 1, 2011. This generated a great response from patients, and Prof. Aoki received many inquiries. We felt energized and decided to make every effort to conduct a successful clinical trial for ALS using HGF and to start a clinical trial for spinal cord injury at Keio University Hospital 1 year later. In addition to the study of HGF, we started another collaborative research project with Prof. Aoki at the beginning of 2011 in which we attempted to establish induced pluripotent stem (iPS) cells from patients with rare familial ALS to elucidate the pathogenetic mechanism of the disease, and had successfully established multiple iPS cell lines by the beginning of March. Everything was going well and nobody expected that such a huge tragedy was about to occur.

\section{March 11, 2011}

A great earthquake struck east Japan at 2:46 pm on March 11, 2011. At the time of the earthquake, I was in Tsukuba City for a research meeting and a lecture. Because of the paralyzed communication system, I could not easily contact my family or laboratory, and because of the suspension of train services, I hurried home in a 
taxi feeling rather uneasy. The highways were completely blocked and I took Route 6 to Tokyo. Route 6 was heavily congested and the taxi could move only very slowly. I was relieved to learn while in the taxi that my family was safe, but I also understood that the iPS cell culture room and flow cytometry facility on the 9th floor of our laboratory might have received a devastating blow. The taxi could not reach Tokyo even by midnight. From the radio in the taxi, I learnt that the earthquake had struck just offshore from the Tohoku district [with a magnitude (Mw) of 9.0, it was the strongest in Japan in recorded history] and that a giant tsunami had struck the coast of Tohoku district just a few minutes after the earthquake. Are my friends in the Tohoku district, including Prof. Aoki, safe? What will happen to the clinical trial for ALS that we had prepared so hard for? Can this country overcome and recover from the earthquake? I had various uneasy thoughts as I finally reached home at dawn the following day.

\section{March 12-14, 2011}

The day after the earthquake, I went to the university and found that the School of Medicine and the hospital was having a really hard time coming to terms with the effects of the earthquake of the previous afternoon. As for my laboratory, the damage to the laboratory rooms on the fifth floor was very slight, but I could not bear to see the damage of the laboratory rooms on the ninth floor: $\mathrm{CO}_{2}$ incubators had fallen down, and disease-specific iPS cells cultured in the incubators, the frozen stock of which had not yet been prepared, were completely dead. We lost all the cells that were going to be used the following week for comprehensive protein expression analyses after a few months in culture and also the iPS cells established from patients with rare familial ALS in the collaborative research with Prof. Aoki. I could barely bring myself to clear away the scattered pieces of broken glass and experimental equipment. Many precision instruments had been damaged, and I was stunned by such an unexpected setback. I wondered how soon we could restart the experiments. However, young staff members in the laboratory courageously worked hard to clean up the mess, and I decided to restart as soon as possible. With the scale of the damage being significant even in Tokyo, I began to imagine how disastrous a situation my friends would be facing in Tohoku, so much closer to the epicenter of the earthquake and the consequent tsunami. I immediately sent the following e-mail to three Professors at Tohoku University: Prof. Masashi Aoki, Prof. Shin-ichi Izumi, my contemporary from Keio University, and Prof. Noriko Osumi, who had long been a collaborator:

"Dear Prof. Aoki, Prof. Osumi and Prof. Izumi,

I am grieved from the heart at the sight of the terrible events in Tohoku in the aftermath of the Tohoku-Pacific Ocean Earthquake.

Are you doing okay?
Please let me know if I can help you in any way.

If you are too busy dealing with the events at hand, don't bother to reply to this mail.

Hideyuki Okano"

Despite the terrible circumstances, Prof. Osumi and Prof. Izumi soon replied to my e-mail saying that they were fine. However, I did not receive any news for a long time from Prof. Aoki, making me feel more and more anxious about him.

At last, on March 14, Prof. Aoki sent me the following mail:

"Dear Prof. Okano,

Thank you for your e-mail.

There was serious damage in Miyagi Prefecture, but fortunately, Tohoku University Hospital and the medical office did not suffer much damage.

However, we cannot yet enter the research building where the medical office is located. My family is also fine, thank you.

All members of the medical staff are doing their best to administer medical care under emergency conditions, but there are serious shortages of medical supplies and food.

In particular, the medical system in coastal areas is devastated, and physicians and nurses in the front line are showing signs of fatigue.

We are waiting for medical (drugs) and other supplies from the rest of the country. Thank you in advance for your help.

Department of Neurology, Tohoku University Masashi Aoki"

I thought that I had to help him at all costs! Therefore, I made every effort to collect supplies for Tohoku University. However, the reality was harsh in that electricity shortages became serious not only in the damaged areas, but also in the Tokyo Metropolitan Area, due to the shutdown of nuclear power plants caused by the earthquake and tsunami and problems in the power transmission system.

\section{March 15-31, 2011}

I maintained close contact with Dr. Hirofumi Kurokawa of Tohoku University Graduate School of Medicine, who had been in the Tokyo Office of Tohoku University since before the earthquake, and we analyzed what supplies were needed. However, because of the marked shortage of goods also in Tokyo, I could not collect enough supplies alone. Therefore, I asked members of the professoriate in Keio University School of Medicine for help, and everyone willingly provided food and daily necessities. I used a vacant room on the second floor of the Center for Integrated Medical Research in the Shinanomachi Campus as a stock room for supplies. The problem was how to transport the supplies to Sendai, where Tohoku University Hospital is located. Needless to say, parcel delivery services to Tohoku had not at that point been 

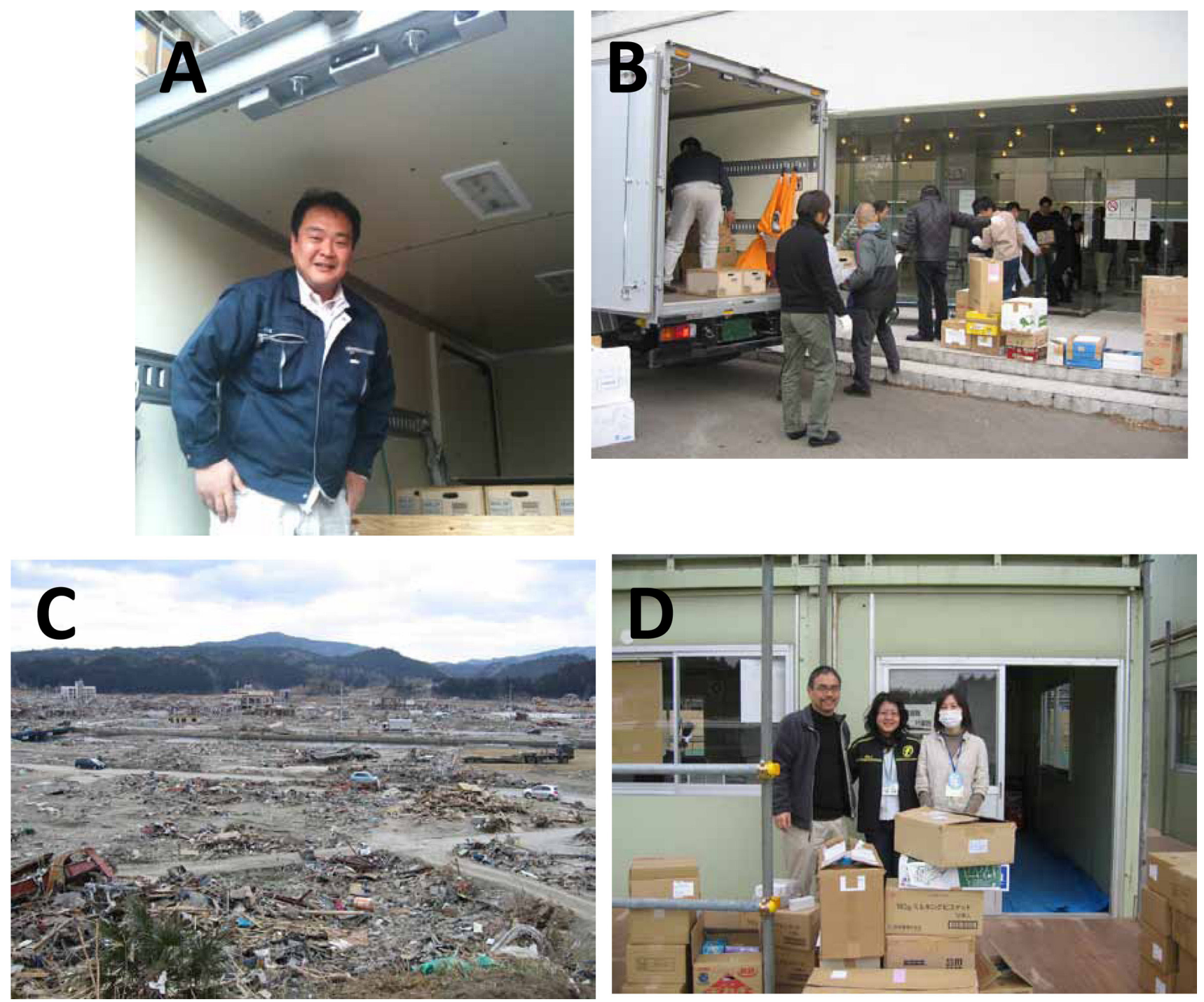

Fig. 1 Supplies of foods and convenience goods transported from Keio to Tohoku.

(A) Supplies are about to leave Keio University on March 25, 2011. Mr. Hajime Kanbayashi kindly accepted our request to deliver supplies from Shinanomachi Campus of Keio University to Tohoku University in one of his company's trucks under very difficult circumstances. (B) Supplies from Keio arrived at Tohoku University on March 25, 2011. Photograph provided by Dr. Hirofumi Kurokawa. (C) The disastrous situation of Minamisanriku on April 3, 2011. Photograph provided by Dr. Hirofumi Kurokawa. (D) Supplies from Keio arrived at the temporary town hall in Minamisanriku on April 3, 2011. Photograph provided by Dr. Hirofumi Kurokawa.

restored, the Tohoku Shinkansen was paralyzed and only vehicles with a special mission and a pass could run on the highways to Tohoku. When searching for a solution, I received a wonderful offer to transport the supplies to Sendai from a transport company whose board of directors includes Heizo Takenaka, Director, Global Security Research Institute, Keio University. Finally, on March 25, we sent the first batch of supplies to Tohoku University, and the supplies arrived the same day (Fig. 1). I received a polite email message of thanks from Prof. Masayuki Yamamoto, Dean of the School of Medicine, Tohoku University, and from Dr. Hirofumi Kurokawa, and I felt a tiny sense of accomplishment. On April 3, supplies from Keio were further delivered from Tohoku University to Minamisanriku, where the most devastating tsunami occurred, by Dr. Kurokawa. Thereafter, parcel delivery services were restored, and a total of three deliveries were made from Keio University to Tohoku University.

During this period, however, Prof. Aoki, Tohoku University Hospital and other medical facilities in the Tohoku district were in a terrible crisis because of electricity shortages. It was a critical situation, particularly for ALS patients requiring artificial respiration and for patients receiving hemodialysis. On March 15, Prof. Aoki 

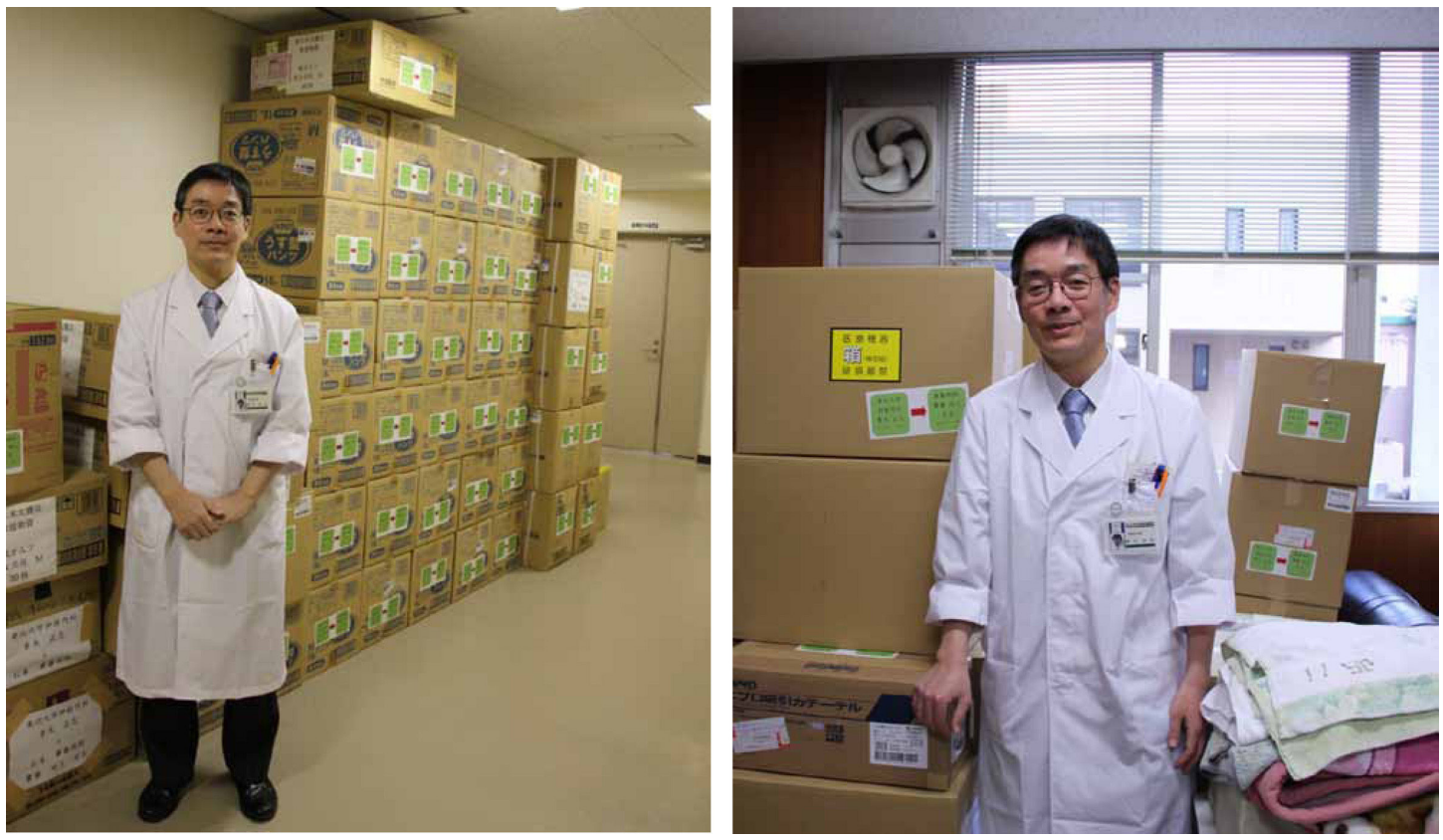

Fig. 2 Supplies of foods and convenience goods were sent to Prof. Aoki from the Japan ALS Association.

See the text for details. Photographs provided by Prof. Masashi Aoki.

sent the following SOS e-mail to professors in the departments of neurology and to his acquaintances in schools of medicine and hospitals throughout the whole country.

"Here in Tohoku, core medical facilities such as Kesennuma City Hospital and Ishinomaki Red Cross Hospital, which are disaster base hospitals in the coastal area, are on the brink of collapse, and supplies of medical equipment, milk powder and food as well as physicians have been sent from Tohoku University, but these are not enough at all. It was decided to shut down all wards of the Sendai Koseinenkin Hospital (400 beds) in the city, and patients are being transported to Tohoku University one after another. Under such circumstances, our hospital has no reserve power and we are becoming fatigued.

Today, two patients on ventilators, along with two staff members, were transported from our department to Yamagata University by helicopter (a physician has to accompany patients during transportation, which places a heavy burden on us).

It would be very helpful if you could send us physician/ nurse teams.

Department of Neurology, Tohoku University Masashi Aoki"

I thought "Why can't they use Self-Defense Force aircraft for medical use?" and I called a friend of mine who was an executive at the Ministry of Defense and also a professor at the National Defense Medical College to request help in the transportation of patients. He came forward and said, "I would like to offer help in transporting patients; however, the Prime Minister is in command of the
Self-Defense Forces, and we cannot act alone.” Through the good offices of the staff of the Ministry of Health, Labour and Welfare and the Cabinet Office, a route to contact the prime minister's official residence was finally established. Thereafter, Prof. Aoki directly called the Prime Minister's official residence on several occasions to request dispatch of the Self-Defense Forces. Every day, Prof. Aoki exchanged information closely with professors at the departments of neurology and physicians of his acquaintance throughout the entire country; with officials of the Ministry of Health, Labour and Welfare; and with the Ministry of Defense and the Air Self-Defense Force. As a result, it was quickly determined where and how patients requiring artificial respiration were to be transported. This wonderful teamwork bore fruit, and many patients with ALS and those in need of maintenance hemodialysis were transported uneventfully by the end of March.

I heard that approximately 100 patients undergoing maintenance hemodialysis at the Tohoku University Hospital and other facilities in Sendai were transported to Hokkaido by the Self-Defense Forces on March 22 and 23. I had to take my hat off to Prof. Aoki; as a new professor, he showed wonderful leadership skills.

\section{April, 2011}

With such extensive efforts being made by Prof. Aoki, naturally, patient groups did not leave him alone. At the beginning of April, the Japan ALS Association sent sup- 


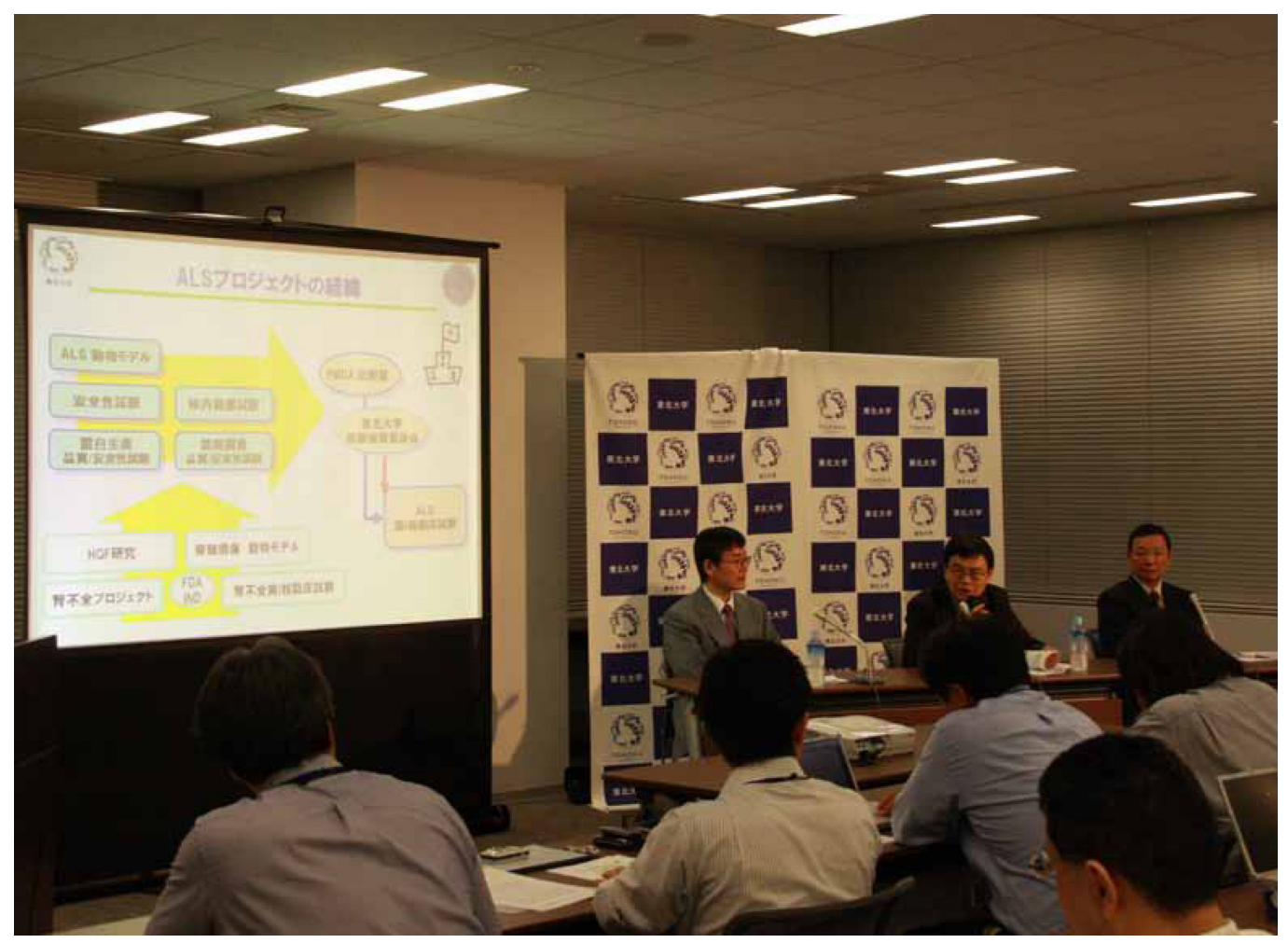

Fig. 3 A press conference about approval for the initiation of the HGF clinical trial for ALS was held on July 8, 2012.

From the left: Prof. Masashi Aoki, the author, Mr. Kunio Iwatani (the President of Kringle Pharma Inc.). Photographs provided by Dr. Fuji Nagami of Tohoku University.

plies to Prof. Aoki (Fig. 2). I was moved to tears by a message from Prof. Aoki saying "We are determined to protect medical and health services for people in this area with all our heart and soul. Thank you in advance for your help."

By April, most patients had been transported to safety, and Prof. Aoki began to send me e-mails about our research. Signs suggesting that preparations for the HGF trial could be resumed soon began to appear. Prof. Aoki also began to send out the strong message, "I would like to make this trial the core of the restoration of Tohoku University." I thought "All right, then, I also have to do my best!" We decided to make every effort to overcome the delay in our research and worked hard to resume research under almost normal conditions at the beginning of April, in the very laboratory rooms damaged by the earthquake.

\section{June 2011 Onward}

On June 3, Kringle Pharma, Inc., submitted notification of a phase I trial plan of HGF treatment for ALS to the PMDA, and finally, at the beginning of July, the initiation of a phase I clinical trial was approved by the PMDA. On
July 8, in the Tokyo Office of Tohoku University, where the control center for the transportation of supplies soon after the earthquake was located, Prof. Aoki, the staff of Kringle Pharma, Inc., and I held a press conference about the receipt of approval for the initiation of the HGF clinical trial (Fig. 3).

The purpose of this phase I clinical trial is to confirm the safety and pharmacokinetics of single and multiple dosing of recombinant HGF protein in ALS patients, and the trial is planned to be conducted at Tohoku University Hospital. Approval from the institutional review board of Tohoku University Hospital was obtained soon after obtaining approval from the PMDA. Hereafter, we propose to select patients fulfilling the trial entry criteria and to actually initiate the phase I trial. I told Prof. Aoki, "We overcame the earthquake, and finally, we can start." He answered, modestly as usual, "Yes, but the real fight begins only now."

It is almost certain that we will face some difficulties while carrying out the trial, as we did in recovering from the earthquake. However, I am sure that our wonderful teams can overcome such difficulties. 


\section{Concluding Remarks}

Focusing on the collaborative research with Prof. Aoki at Tohoku University, I have described the effects of the earthquake and our recovery from it. We enthusiastically embrace the challenge of this research precisely because neural regeneration as a medical treatment is a difficult task that no one has yet successfully achieved. Success will come with the integration of basic and clinical medical systems beyond the realm of universities, a smooth industry-university cooperation system and ample public funds, which are available only in wealthy societies. Even under normal circumstances, these are not easy tasks. Naturally, the heavy blow of the earthquake was a great setback, but on the other hand, it reiterated our faith in the collaborative process and underlined our attitude of "not bowing to any hardship." In addition, it was impressive that a person who had just been appointed professor was able to display such exemplary leadership. I have learned much from Prof. Aoki, and I am grateful for the opportunity to tell this story of triumph over adversity.

\section{Acknowledgments}

I wish to thank all my colleagues, especially Professor Masashi Aoki, for the motivation to write this article, and Dr. Hirofumi Kurokawa for generous supplies of photographs taken in Tohoku. The collaborative work on HGF was carried out by the Department of Physiology and the Department of Orthopedic Surgery of Keio University and the Department of Neurology of Tohoku University and was supported by Grants-in-aid for Scientific Research from JSPS and the Ministry of Education, Culture, Sports, Science and Technology of Japan (MEXT); the Project for Realization of Regenerative Medicine and Support for the Core Institutes for iPS Cell Research from MEXT; a Grant-in-aid for the Global COE program from MEXT to Keio University; Research on Measures for Intractable Diseases from the Japanese Ministry of Health, Labor and Welfare of Japan; and by "Super Special Consortia for Supporting the Development of Cutting-edge Medical Care."

\section{References}

1. Nakamura T, Nawa K, Ichihara A : Partial purification and characterization of hepatocyte growth factor from serum of hepatectomized rats. Biochem Biophys Res Commun 1984; 122: 14501459. [Medline] [CrossRef]

2. Nakamura T, Nishizawa T, Hagiya M, Seki T, Shimonishi M, Sugimura A, Tashiro K, Shimizu S.: Molecular cloning and expression of human hepatocyte growth factor. Nature 1989; 342: 440-443. [Medline] [CrossRef]

3. Sun W, Funakoshi H, Nakamura T : Overexpression of HGF retards disease progression and prolongs life span in a transgenic mouse model of ALS. J Neurosci 2002; 22: 6537-6548. [Medline]

4. Kitamura K, Iwanami A, Nakamura M, Yamane J, Watanabe K, Suzuki Y, Miyazawa D, Shibata S, Funakoshi H, Miyatake S, Coffin RS, Nakamura T, Toyama Y, Okano H.: Hepatocyte growth factor promotes endogenous repair and functional recovery after spinal cord injury. J Neurosci Res 2007; 85: 2332-2342. [Medline] [CrossRef]

5. Nagai M, Aoki M, Miyoshi I, Kato M, Pasinelli P, Kasai N, Brown RH Jr, Itoyama Y : Rats expressing human cytosolic copper-zinc superoxide dismutase transgenes with amyotrophic lateral sclerosis: associated mutations develop motor neuron disease. J Neurosci 2001; 21: 9246-9254. [Medline]

6. Ishigaki A, Aoki M, Nagai M, Warita H, Kato S, Kato M, Nakamura T, Funakoshi H, Itoyama Y.: Intrathecal delivery of hepatocyte growth factor from amyotrophic lateral sclerosis onset suppresses disease progression in rat amyotrophic lateral sclerosis model. J Neuropathol Exp Neurol 2007; 66: 1037-1044. [Medline] [CrossRef]

7. Kitamura K, Fujiyoshi K, Yamane JI, Toyota F, Hikishima K, Nomura T, Funakoshi H, Nakamura T, Aoki M, Toyama Y, Okano H, Nakamura M.: Human hepatocyte growth factor promotes functional recovery in primates after spinal cord injury. PLoS ONE (In Press). [Medline]

8. Ogawa Y, Sawamoto K, Miyata T, Miyao S, Watanabe M, Nakamura M, Bregman BS, Koike M, Uchiyama Y, Toyama Y, Okano $\mathrm{H}$ : Transplantation of in vitro-expanded fetal neural progenitor cells results in neurogenesis and functional recovery after spinal cord contusion injury in adult rats. J Neurosci Res 2002; 69: 925933. [Medline] [CrossRef]

9. Iwanami A, Yamane J, Katoh H, Miyao S, Watanabe M, Nakamura M, Bregman BS, Koike M, Uchiyama Y, Toyama Y, Okano H.: Establishment of graded spinal cord injury model in a nonhuman primate: the common marmoset. J Neurosci Res 2005; 80: 172-181. [Medline] [CrossRef]

10. Okada S, Ishii K, Yamane J, Iwanami A, Ikegami T, Katoh H, Iwamoto Y, Nakamura M, Miyoshi $\mathrm{H}$, Okano HJ, Contag $\mathrm{CH}$, Toyama Y, Okano H.: In vivo imaging of engrafted neural stem cells: its application in evaluating the optimal timing of transplantation for spinal cord injury. FASEB J 2005; 19: 1839-1841. [Medline] 